\title{
Clarifying surgery and anesthesia partnerships in response to global surgery and the World Health Organization
}

\author{
Walter D. Johnson, MD, MBA, MPH • Emmanuel M. Makasa, MD
}

Received: 30 July 2019/Revised: 30 July 2019/Accepted: 30 July 2019/Published online: 16 September 2019

(C) Canadian Anesthesiologists' Society 2019

\section{To the Editor,}

We read with interest the recently published manuscript entitled, "Global surgery and the World Health Organization: indispensable partners to achieve triple billion goals." ${ }^{1}$ We thank Dr. Reddy and colleagues for their efforts to highlight the work of the World Health Organization (WHO) in surgical care and anesthesia. Nevertheless, these attempts to explain the internal workings and agenda of WHO in the context of the Thirteenth General Programme of Work (GPW13), World Health Assembly (WHA) resolutions, and Sustainable Development Goals (SDGs), fall far short.

We would like to correct several inaccuracies in this report to clarify for your readers WHO function, work, and goals.

First, the GPW13 is a five-year agenda (not a six-year agenda as indicated by Reddy et al. ), ${ }^{1}$ similar to the WHO Director-General's term of office. The GPW13 covers the years 2019-2023 and obtained final approval at the 71st WHA in May 2018. ${ }^{\mathrm{A}}$ The GPW13 is directly linked to the SDGs and their targets, and provides clear direction to the work of the WHO over these five years. It provides a vision, rooted in Article 1 of the WHO's constitution-of a

This letter is accompanied by a reply. Please see Can J Anesth 2020; this issue.

W. D. Johnson, MD, MBA, MPH ( $ه)$

Lead Emergency and Essential Surgical Care Programme, WHO,

Geneva, Switzerland

e-mail: johnsonw@who.int

E. M. Makasa, MD

Wits Centre of Surgical Care for Primary Health and Sustainable Development, University of the Witwatersrand, Johannesburg, South Africa world in which all people attain the highest possible standard of health and well-being - and summarizes the WHO's mission, which is to promote health, keep the world safe, and serve the vulnerable. This indeed covers the triple billion goals over five years.

While it is true that the GPW13 does include the sentence: "[t]here is also a need to increase availability of

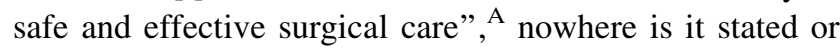
implied that using GPW13 to "strengthen surgical, obstetric, and anesthesia (SOA) systems will enable the global health community and WHO to attain the triple billion goals." 1

Second, the WHA resolution WHA68.15 on strengthening emergency and essential surgical care and anesthesia as a component of universal health coverage (UHC), was passed unanimously at the 68th WHA in May $2015 .^{2}$ Dr. Emmanuel Makasa was one of the principal drivers of this resolution while serving as Health Attaché for the Zambian Permanent Mission to the United Nations Organization in Geneva (2012-2017). While "emergency and essential surgical care and anaesthesia" supports the attainment of good obstetrics and emergency care outcomes, the two areas of work are addressed in separate WHO documents and resolutions. Nevertheless, while this association within the resolution is implied, it is perhaps an overstatement to say "WHO member states declared SOA care as both 'critical' and 'integral' components to achieve global health goals (UHC, primary healthcare $[\mathrm{PHC}]$ and emergency care) through WHA 68.15." Similarly, regarding the statement that

\footnotetext{
A World Health Organization. Thirteenth General Programme of Work. Promote Health - Keep the World Safe - Serve the Vulnerable - 2018. Available from URL: https://apps.who.int/iris/bitstream/ handle/10665/324775/WHO-PRP-18.1-eng.pdf (accessed August 2019).
} 
passage of WHA68.15 created a . . ."paradigm shift . . . as it established SOA care as an essential component of the major global health priority areas of PHC, UHC, and emergency care" as Reddy et al. ${ }^{1}$ state-we strongly agree that it highlights the primary level of an integrated health system and probably implies both primary and emergency care content. We also agree that obstetric surgery is an integral component of surgical care, and for many, emergency surgical care is part of the overall emergency care continuum. We feel this could be elucidated a bit more accurately.

Third, the United Nations' SDGs were launched as a replacement for the Millennium Development Goals in 2015 to cover the Era of Sustainable Development 2015$2030{ }^{\mathrm{B}}$ There are 17 SDGs with 169 targets and 232 indicators. Specifically, SDG3- "Ensure healthy lives and promote well-being for all at all ages" - contains 13 targets and 26 indicators. Reddy et al. risk misinformation by stating that "The triple billion targets are aligned with and designed to support the attainment of SDG3, the United Nations' global target to promote health and wellbeing - an essential strand of its eighteen-goal plan to eradicate poverty by 2030." As stated above, the WHO triple billion goals support all 17 SDGs (not 18 as stated in error by Reddy et al.). ${ }^{1}$ Furthermore, only SDG1 is a goal to eradicate poverty by 2030 . In toto, the SDGs "provide a shared blueprint for peace and prosperity for people and the planet, now and into the future." $\mathrm{B}$

Fourth, while we emphatically and actively support the development of National Surgical, Obstetric and Anesthesia Plans (NSOAPs) that are fully embedded within the national health policy, strategy or plan of member States, ${ }^{3,4}$ we cannot agree with the statement by Reddy et al. that "[w]ithout actively supporting the development of NSOAPs, the WHO and member states will fall short of their shared health goals. ${ }^{1}$ We do not see that NSOAPs are the only mechanism to achieve the SDGs, particularly as not all countries have or require NSOAPs (most of the developed world), and the fact that not all countries will have the opportunity to develop an NSOAP by 2030 , although they may make substantial progress in achieving the SDGs.

Lastly, we question the validity of their statement that "increased collaboration between the WHO and nation states is needed to strengthen and institutionalize data systems at the national level." ${ }^{1}$ This seems to imply that at some times and in some places the WHO does not collaborate well with member states. The WHA is composed of health ministries of all 194 member states and is the governing body of the WHO, which approves the global health agenda. Additionally, the WHO works with all 194 member states, across six regions, and from more than 150 country offices. While data collection and data systems have inherent challenges, poor collaboration between the WHO and member states is generally not the issue.

While we realize that approximately one third of the global burden of disease requires surgical care and anesthesia, and that this is inextricably linked to the WHO agenda, including SDGs, UHC, resolutions, and GPW13, the links between these global agendas need to be clarified and portrayed accurately.

Acknowledgements The views expressed by the authors in this article are their own and are not an official response from the WHO.

Conflicts of interest None declared.

Editorial responsibility This submission was handled by Dr. Hilary P. Grocott, Editor-in-Chief, Canadian Journal of Anesthesia.

\section{References}

1. Reddy CL, Patterson RH, Caddell L, et al. Global surgery and the World Health Organization: indispensable partners to achieve triple billion goals. Can J Anesth 2019. https://doi.org/10.1007/ s12630-019-01426-4.

2. World Health Assembly. Resolution WHA68.15.Agenda item 17.1 - 26 May 2015. Available from URL: https://apps.who.int/gb/ ebwha/pdf_files/WHA68/A68_R15-en.pdf (accessed August 2019).

3. Johnson W, Lin Y, Mukhopadhyay, Meara J. Surgical Care Systems Strengthening: Developing National Surgical, Obstetric and Anaesthesia Plans. Geneva, Switzerland: WHO Press; 2017.

4. Albutt K, Citron I, Sonderman, K, et al. Policy Brief: National Surgical Obstetric and Anaesthesia Planning: Process and Consensus Recommendations. Harvard Press; 2018.

Publisher's Note Springer Nature remains neutral with regard to jurisdictional claims in published maps and institutional affiliations.

${ }^{\mathrm{B}}$ United Nations. Sustainable Development Goals. 2015. Available from URL: https://sustainabledevelopment.un.org/ (accessed August 2019). 